\title{
Detecting patterns of fraudulent behavior in forensic accounting*
}

\author{
Boris Kovalerchuk ${ }^{1}$, Evgenii Vityaev ${ }^{2}$ \\ ${ }^{1}$ Dept. of Computer Science, Central Washington University \\ Ellensburg, WA 98926, USA \\ borisk@cwu.edu \\ ${ }^{2}$ Institute of Mathematics, Russian Academy of Sciences, \\ Novosibirsk, 630090, Russia \\ vityaev@math.nsc.ru
}

\begin{abstract}
Often evidence from a single case does not reveal any suspicious patterns to aid investigations in forensic accounting and other forensic fields. In contrast, correlation of sets of evidence from several cases with suitable background knowledge may reveal suspicious patterns. Link Discovery (LD) has recently emerged as a promising new area for such tasks. Currently LD mostly relies on deterministic graphical techniques. Other relevant techniques are Bayesian probabilistic and causal networks. These techniques need further development to handle rare events. This paper combines first-order logic (FOL) and probabilistic semantic inference (PSI) to address this challenge. Previous research has shown this approach is computationally efficient and complete for statistically significant patterns. This paper shows that a modified method can be successful for discovering rare patterns. The method is illustrated with an example of discovery of suspicious patterns.
\end{abstract}

\section{Introduction}

Forensic accounting is a field that deals with possible illegal and fraudulent financial transactions [3]. One current focus in this field is the analysis of funding mechanisms for terrorism where clean money (e.g., charity money) and laundered money are both used [1] for a variety of activities including acquisition and production of weapons and their precursors. In contrast, traditional illegal businesses and drug trafficking make dirty money appear clean [1].

There are many indicators of possible suspicious (abnormal) transactions in traditional illegal business. These include (1) the use of several related and/or unrelated accounts before money is moved offshore, (2) a lack of account holder concern with commissions and fees [2], (3) correspondent banking transactions to offshore shell banks [2], (4) transferor insolvency after the transfer or insolvency at the time of

\footnotetext{
${ }^{*}$ Kovalerchuk, B., Vityaev, E., Detecting patterns of fraudulent behavior in forensic accounting, In Proc. of the Seventh International Conference "Knowledge-based Intelligent Information and Engineering on Systems", Oxford, UK, Sept, 2003, part 1, pp. 502-509
} 
transfer, (5) wire transfers to new places [4], (6) transactions without identifiable business purposes, and (7) transfers for less than reasonably equivalent value [5].

Some of these indicators can be easily implemented as simple flags in software. However, indicators such as wire transfers to new places produce a large number of 'false positive' suspicious transactions. Thus, the goal is to develop more sophisticated mechanisms based on interrelations among many indicators. To meet these challenges link analysis software for forensic accountants, attorneys and fraud examiners such as NetMap, Analyst's Notebook and others [4-7] have been and are being developed.

Here we concentrate on fraudulent activities that are closely related to terrorism such as transactions without identifiable business purposes. The problem is that often an individual transaction does not reveal that it has no identifiable business purpose or that it was done for no reasonably equivalent value. Thus, we develop a technique that searches for suspicious patterns in the form of more complex combinations of transactions and other evidence using background knowledge.

The specific tasks in automated forensic accounting related to transaction monitoring systems are the identification of suspicious and unusual electronic transactions and the reduction in the number of 'false positive' suspicious transactions by using inexpensive, simple rule-based systems, customer profiling, statistical techniques, neural networks, fuzzy logic and genetic algorithms [1]. This paper combines the advantages of first-order logic (FOL) and probabilistic semantic inference (PSI) [8] for these tasks. We discover the following transaction patterns from ordinary or distributed databases that are related to terrorism and other illegal activities:

- a normal pattern (NP) - a Manufacturer Buys a Precursor \& Sells the Result of manufacturing (MBPSR);

- a suspicious (abnormal) pattern (SP) - a Manufacturer Buys a Precursor \& Sells the same Precursor (MBPSP);

- a suspicious pattern (SP) - a Trading Co. Buys a Precursor and Sells the same Precursor Cheaper (TBPSPC);

- a normal pattern (NP) -- a Conglomerate Buys a Precursor \& Sells the Result of manufacturing (CBPSR).

\section{Example}

Consider the following example. Table 1 contains transactions with the attributes seller, buyer, item sold, amount, cost and date and Table 2 describes the types of companies and items sold.

Table 1. Transactions records

\begin{tabular}{|c|c|c|c|c|c|l|}
\hline Record ID & Seller & Buyer & Item sold & Amount & Cost & Date \\
\hline 1 & Aaa & Ttt & Td & $1 \mathrm{t}$ & $\$ 100$ & $03 / 05 / 99$ \\
\hline 2 & Bbb & Ccc & Td & $2 \mathrm{t}$ & $\$ 100$ & $04 / 06 / 98$ \\
\hline 3 & Ttt & Qqq & Td & $1 \mathrm{t}$ & $\$ 100$ & $05 / 05 / 99$ \\
\hline 4 & Qqq & Ccc & Pd & $1.5 \mathrm{t}$ & $\$ 100$ & $05 / 05 / 99$ \\
\hline 5 & Ccc & Ddd & Td & $2.0 \mathrm{t}$ & $\$ 200$ & $08 / 18 / 98$ \\
\hline 6 & Ddd & Ccc & Pd & $3.0 \mathrm{t}$ & $\$ 400$ & $09 / 18 / 98$ \\
\hline
\end{tabular}


We assemble a new Table 3 from Tables 1 and 2 to look for suspicious patterns. For instance, row 1 in Table 3 is a combination of row 1 from Table 1 and rows 1 and 4 from Table 2 that contain types of companies and items. Table 3 does not indicate suspicious patterns immediately, but we can generate pairs of records from Table 3 that can be mapped to patterns listed above using a pattern-matching algorithm $A$. The algorithm A analyzes pairs of records in Table 3 . For simplicity, we can assume that a new table with 18 attributes is formed to represent pairs of records from Table 3. Each record in Table 3 contains nine attributes.

Table 2. Company types and item types

\begin{tabular}{|c|c|l|l|l|}
\hline Record ID & $\begin{array}{c}\text { Company name } \\
\text { (seller/buyer) }\end{array}$ & Company type & Item & Item type in process PP \\
\hline 1 & Aaa & Trading & Td & Precursor \\
\hline 2 & Bbb & Unknown & Pd & Product \\
\hline 3 & Ccc & Trading & Rd & Precursor \\
\hline 4 & $\mathrm{Ttt}$ & Manufacturing & & \\
\hline 5 & Ddd & Manufacturing & & \\
\hline 6 & Qqq & Conglomerate & & \\
\hline
\end{tabular}

Table 3. Combined data records

\begin{tabular}{|l|l|l|l|l|l|l|l|l|l|}
\hline Record ID & Seller & $\begin{array}{l}\text { Seller } \\
\text { type }\end{array}$ & Buyer & $\begin{array}{l}\text { Buyer } \\
\text { type }\end{array}$ & $\begin{array}{l}\text { Item } \\
\text { sold }\end{array}$ & Item type & Amount & Price & Date \\
\hline & 1 & 2 & 3 & 4 & 5 & 6 & 7 & 8 & 9 \\
\hline 1 & Aaa & trading & $\mathrm{Ttt}$ & Manuf. & $\mathrm{Td}$ & Precursor & $1 \mathrm{t}$ & $\$ 100$ & $03 / 05 / 99$ \\
\hline 2 & Bbb & unknown & Ccc & Trading & $\mathrm{Td}$ & Precursor & $2 \mathrm{t}$ & $\$ 100$ & $04 / 06 / 98$ \\
\hline 3 & $\mathrm{Ttt}$ & manuf. & Qqq & Congl. & $\mathrm{Td}$ & Precursor & $1 \mathrm{t}$ & $\$ 100$ & $05 / 05 / 99$ \\
\hline 4 & Qqq & Congl. & Ccc & Trading & $\mathrm{pd}$ & Product & $1.5 \mathrm{t}$ & $\$ 100$ & $06 / 23 / 99$ \\
\hline 5 & Ccc & Trading & Ddd & Manuf. & $\mathrm{td}$ & Precursor & $2.0 \mathrm{t}$ & $\$ 200$ & $08 / 18 / 98$ \\
\hline 6 & Ddd & Manuf & Ccc & Trading & $\mathrm{pd}$ & Product & $3.0 \mathrm{t}$ & $\$ 400$ & $09 / 18 / 98$ \\
\hline
\end{tabular}

Thus, we map pairs of records in Table 3 into patterns:

$A(\# 5, \# 6)=$ MBPSR, that is a pair of records \#5 and \#6 from Table 3 indicates a normal pattern -- a manufacturer bought a precursor and sold product ;

In contrast, two other pairs indicate suspicious patterns:

$A(\# 1, \# 3)=$ MBPSP, that is a manufacturer bought a precursor and sold the same precursor;

$A(\# 2, \# 5)=$ TBPSPC, that is a trading company bought a precursor and sold the same precursor cheaper.

Now let us assume that we have a database of $10^{5}$ transactions as in Table 1 . Then Table 3 will have all pairs of them, i.e., about $5^{*} 10^{9}$. Statistical computations can reveal a distribution of these pairs into patterns as shown in Table 4.

Table 4. Statistical characteristics

\begin{tabular}{|l|l|l|l|}
\hline Pattern & Type & Frequency, \% & Approximate number of cases \\
\hline MBPSR & normal & 55 & $0.55 * 5 * 10^{9}$ \\
\hline
\end{tabular}




\begin{tabular}{|l|l|l|c|}
\hline MBPSP & suspicious & 0.1 & 100 \\
\hline CBPSR & normal & 44.7 & $0.44 * 5 * 10^{9}$ \\
\hline TBPSPC & suspicious & 0.2 & 200 \\
\hline
\end{tabular}

Thus, we have 300 suspicious transactions. This is $0.3 \%$ of the total number of transactions and about $6^{*} 10^{-6} \%$ of the total number of pairs analyzed. It shows that finding such transactions is like finding a needle in a haystack. The automatic generation of patterns/hypotheses descriptions is a major challenge. This includes generating MBPSP and TBPSPC descriptions automatically. We do not assume that we already know that MBPSP and TBPSPC are suspicious. One can ask: "Why do we need to discover these definitions (rules) automatically?" A manual way can work if the number of types of suspicious patterns is small and an expert is available. For multistage money-laundering transactions, this is difficult to accomplish manually. It is possible that many laundering transactions were processed before money went offshore or was used for illegal purposes. Our approach to identify suspicious patterns is to discover highly probable patterns and then negate them. We suppose that a highly probable pattern should be normal. In more formal terms, the main hypothesis $(\mathrm{MH})$ is:

If $Q$ is a highly probable pattern (>0.9) then $Q$ constitutes a normal pattern and not $(Q)$ can constitute a suspicious (abnormal) pattern.

Table 5 outlines an algorithm based on this hypothesis to find suspicious patterns. The algorithm is based first-order logic and probabilistic semantic inference [8].

Table 5. Algorithm steps for finding suspicious patterns based on the main hypotheis $(\mathrm{MH})$

1 Discover patterns in a database such as MBPSR in a form MBP $\Rightarrow \mathrm{SR}$, that is, as a Horn clause $A_{1} \& A_{2} \& \ldots \& A_{n-1} \Rightarrow A_{n}$ (see [8] for mathematical detail).

1.1.Generate a set of predicates $\mathbf{Q}=\left\{\mathrm{Q}_{1}, \mathrm{Q}_{2}, \ldots, \mathrm{Q}_{\mathrm{m}}\right\}$ and first order logic sentences $A_{1}, A_{2}, \ldots, A_{n}$ based on those predicates. For instance, $Q_{1}$ and $A_{1}$ could be defined as follows: $\mathrm{Q}_{1}(\mathrm{x})=1 \Leftrightarrow \mathrm{x}$ is a trading company and $\mathrm{A}_{1}(\mathrm{a}, \mathrm{b})=\mathrm{Q}_{1}(\mathrm{a}) \& \mathrm{Q}_{1}(\mathrm{~b})$, where $\mathrm{a}$ and $\mathrm{b}$ are companies.

1.2. Compute a probability $P$ that pattern $A_{1} \& A_{2} \& \ldots \& A_{n-1} \Rightarrow A_{n}$ is true on a given database. This probability is computed as a conditional probability of conclusion $A_{n}$ under assumption that If-part $A_{1} \& A_{2} \& \ldots \& A_{n-1}$ is true, that is $P\left(A_{n} / A_{1} \& A_{2} \& \ldots \& A_{n-1}\right)=$ $=N\left(A_{n} / A_{1} \& A_{2} \& \ldots \& A_{n-1}\right) / N\left(A_{1} \& A_{2} \& \ldots \& A_{n-1} \& A_{n}\right)$, where $N\left(A_{n} / A_{1} \& A_{2} \& \ldots \& A_{n-1}\right)$ is the number of $A_{n} / A_{1} \& A_{2} \& \ldots \& A_{n-1}$ cases and $N\left(A_{1} \& A_{2} \& \ldots \& A_{n-1} \& A_{n}\right)$ is the number of $\mathrm{A}_{1} \& \mathrm{~A}_{2} \& \ldots \& \mathrm{~A}_{\mathrm{n}-1} \& \mathrm{~A}_{\mathrm{n}}$ cases.

1.3. Compare $P\left(A_{1} \& A_{2} \& \ldots \& A_{n-1} \Rightarrow A_{n}\right)$ with a threshold $T$, say $T=0.9$.

If $\mathrm{P}\left(\mathrm{A}_{1} \& \mathrm{~A}_{2} \& \ldots \& \mathrm{~A}_{\mathrm{n}-1} \Rightarrow \mathrm{A}_{\mathrm{n}}\right)>\mathrm{T}$ then a database is "normal". A user can select another value of threshold $\mathrm{T}$, e.g., $\mathrm{T}=0.98$. If $\mathrm{P}(\mathrm{MBP} \Rightarrow \mathrm{SR})=0.998$, then $\mathrm{DB}$ is normal for 0.98 too.

1.4. Test statistical significance of $P\left(A_{1} \& A_{2} \& \ldots \& A_{n-1} \Rightarrow A_{n}\right)$. We use the Fisher criterion [8] to test statistical significance.

2 Negate patterns. If database is "normal" $\left(\mathrm{P}\left(\mathrm{A}_{1} \& \mathrm{~A}_{2} \& \ldots \& \mathrm{~A}_{\mathrm{n}-1} \Rightarrow \mathrm{A}_{\mathrm{n}}\right)>\mathrm{T}=0.9\right.$ and $A_{1} \& A_{2} \& \ldots \& A_{n-1} \Rightarrow A_{n}$ is statistically significant then negate $A_{1} \& A_{2} \& \ldots \& A_{n-1} \Rightarrow A_{n}$ to produce a negated pattern $A_{1} \& A_{2} \& \ldots \& A_{n-1} \Rightarrow^{\urcorner} A_{n}$.

3 Compute the probability of the negated pattern $\mathrm{P}\left(\mathrm{A}_{1} \& \mathrm{~A}_{2} \& \ldots \& \mathrm{~A}_{\mathrm{n}-1} \Rightarrow^{7} \mathrm{~A}_{\mathrm{n}}\right)=$ 1- $\mathrm{P}\left(\mathrm{A}_{1} \& \mathrm{~A}_{2} \& \ldots \& \mathrm{~A}_{\mathrm{n}-1} \Rightarrow \mathrm{A}_{\mathrm{n}}\right)$.

In the example above, it is $1-0.998=0.002$. 
4 Analyze database records that satisfy $\mathrm{A}_{1} \& \mathrm{~A}_{2} \& \ldots \& \mathrm{~A}_{\mathrm{n}-1} \&{ }^{7} \mathrm{~A}_{\mathrm{n}}$. for possible false alarm. Really suspicious records satisfy the property $\left.A_{1} \& A_{2} \& \ldots \& A_{n-} \&\right\urcorner A_{n}$, but normal records also can satisfy this property.

To minimize computations we generate randomly a representative part of all possible pairs of records such as shown in Table 4 . Then an algorithm finds highly probable $(\mathrm{P}>\mathrm{T})$ Horn clauses. Next, these clauses are negated as described in Table 5.

After that, a full search of records in the database is performed to find records that satisfy the negated clauses. According to our main hypothesis (MH) this set of records will contain suspicious records and the search for "red flag" transactions will be significantly narrowed. Use of the property of monotonicity is another tool we use to minimize computations. The idea is based on a simple observation: If $A 1 \& A_{2} \& \ldots \& A_{n-1} \Rightarrow B$ represents a suspicious pattern then $A_{1} \& A_{2} \& \ldots \& A_{n-1} \& A_{n} \Rightarrow B$ is suspicious too. Thus, one does not need to test clause $A_{1} \& A_{2} \& \ldots \& A_{n-1} \& A_{n} \Rightarrow B$ if $A_{1} \& A_{2} \& \ldots \& A_{n-1} \Rightarrow B$ is already satisfied.

\section{Hypothesis Testing}

One of the technical aims of this paper is to design tests and simulation experiments for this thesis. We designed two test experiments:

1. Test 1: Generate a relatively large Table 4 that includes a few suspicious records MBPSP and TBPSPC. Run a data-mining algorithm (MMDR [8]) to discover as many highly probable patterns as possible. Check that patterns MBPSR and CBPSR are among them. Negate MBPSR and CBPSR to produce patterns MBPSP and TBPSPC. Run patterns MBPSP and TBPSPC to find all suspicious records consistent with them.

2. Test 2: Check that other highly probable patterns found are normal; check that their negations are suspicious patterns (or contain suspicious patterns).

A positive result of Test 1 will confirm our hypothesis (statement) for MBPSR and CBPSR and their negations. Test 2 will confirm our statement for a wider set of patterns. In this paper we report results of conducting Test 1 . The word "can" is the most important in our statement/hypothesis. If the majority of $\operatorname{not}(\mathrm{Q})$ patterns are consistent with an informal and intuitive concept of suspicious pattern then this hypothesis will be valid. If only a few of the not(Q) rules (patterns) are intuitively suspicious then the hypothesis will not be of much use even if it is formally valid.

A method for Test 1 contains several steps:

- Create a Horn clause: MBP $\Rightarrow$ SR.

- Compute a probability that $\mathrm{MBP} \Rightarrow \mathrm{SR}$ is true on a given database. Probability $\mathrm{P}(\mathrm{MBP} \Rightarrow \mathrm{SR})$ is computed as a conditional probability

$\mathrm{P}(\mathrm{SR} / \mathrm{MBP})=\mathrm{N}(\mathrm{SR} / \mathrm{MBP}) / \mathrm{N}(\mathrm{MBP})$, where $\mathrm{N}(\mathrm{SR} / \mathrm{MBP})$ is the number of MBPSR cases and $\mathrm{N}(\mathrm{MBP})$ is the number of MBP cases.

- Compare $\mathrm{P}(\mathrm{MBP} \Rightarrow \mathrm{SR})$ with 0.9. If $\mathrm{P}(\mathrm{MBP} \Rightarrow \mathrm{SR})>0.9$ then a database is "normal". For instance, P(SR/MBP) can be 0.998 .

- Test the statistical significance of $\mathrm{P}(\mathrm{MBP} \Rightarrow \mathrm{SR})$. We use Fisher criterion [8] to test statistical significance. 
- If the database is "normal" $(\mathrm{P}(\mathrm{MBP} \Rightarrow \mathrm{SR})>\mathrm{T}=0.9)$ and if $\mathrm{P}(\mathrm{MBP} \Rightarrow \mathrm{SR})$ is statistically significant then negate $\mathrm{MBP}=>\mathrm{SR}$ to produce ${ }^{\urcorner}(\mathrm{MBP} \Rightarrow \mathrm{SR})$. Threshold $\mathrm{T}$ can have another value too.

- Compute probability for a negated pattern $\mathrm{P}\left(\mathrm{MBP} \Rightarrow{ }^{\urcorner}(\mathrm{SR})\right)$. In the example above it is $1-0.998=0.002$.

- Analyze database records that satisfy MBP and $\urcorner(\mathrm{SR})$. For instance, really suspicious MBPSP records satisfy property MBP and $\urcorner(\mathrm{SR})$, but other records also can satisfy this property too. For instance, MBPBP records (a manufacturer bought a precursor twice) can be less suspicious than MBPSP.

Thus, if the probability $\mathrm{P}(\mathrm{SR} / \mathrm{MBP})$ is high (0.9892) and statistically significant then a normal pattern MBPSR is discovered. Then suspicious cases are among the cases where MBP is true but the conclusion SR is not true. We collect these cases and analyze the actual content of the then-part of the clause MBP $=>$ SR. The set ${ }^{7} \mathrm{SR}$ can contain a variety of entities. Some of them can be very legitimate cases. Therefore, this approach does not guarantee that we find only suspicious cases, but the method narrows the search to a much smaller set of records. In the example above the search is narrowed to $0.2 \%$ of the total cases.

\section{Experiment}

We generated two synthesized databases with attributes shown in Table 4. The first one does not have suspicious records MBPSP and TBPSPC. A second database contains few such records. Using a Machine Method for Discovery Regularities (MMDR) [8] we were able to discover MBPSR and CBPSR normal patterns in both databases.

Table 6. Database with suspicious cases

\begin{tabular}{|l|c|c|}
\hline \multirow{2}{*}{ Pattern } & \multicolumn{2}{|c|}{ Probability $\mathrm{P}\left(\mathrm{A}_{1} \& \mathrm{~A}_{2} \& \ldots \& \mathrm{~A}_{\mathrm{n}-1} \Rightarrow \mathrm{A}_{\mathrm{n}}\right)$} \\
\cline { 2 - 3 } & $\begin{array}{c}\text { In database without } \\
\text { suspicious cases }\end{array}$ & $\begin{array}{c}\text { In database with } \\
\text { suspicious cases }\end{array}$ \\
\hline Normal pattern, $\mathrm{MBP} \Rightarrow \mathrm{SR}$ & $>0.95$ & $>0.9$ \\
\hline Negated pattern $\mathrm{MBP} \Rightarrow\urcorner(\mathrm{SR})$ & $<0.0 .5$ & $<0.1$ \\
\hline Normal pattern $\mathrm{CBP}=>\mathrm{SR}$ & $>0.95$ & $>0.9$ \\
\hline Negated pattern $\mathrm{CBP} \Rightarrow\urcorner(\mathrm{SR})$ & $<0.05$ & $<0.05$ \\
\hline
\end{tabular}

The MMDR method worked without any advanced information that these patterns are in data. In the database without suspicious cases, negated patterns MBP $\Rightarrow\urcorner$ (SR) and $\mathrm{CBP} \Rightarrow{ }^{\urcorner}(\mathrm{SR})$ contain cases that are not suspicious. For instance, MBP $\Rightarrow \mathrm{BP}$, that is, a manufacturer that already bought precursors (transaction record 1) bought them again (transaction record 2). The difference in probabilities for $\mathrm{MBP} \Rightarrow{ }^{7}(\mathrm{SR})$ in the two databases points out actually suspicious cases. In our computational experiments, the total number of regularities found is 41 . The number of triples of companies (i.e., pairs of transactions) captured by regularities is 1531 out of total 2772 tri- 
ples generated in the experiment. Table 7 depicts some statistically significant regularities found. Attributes New_Buyer_type and New_Item_type belong to the second record in a pair of records $(\mathrm{R} 1, \mathrm{R} 2)$. Individual records are depicted in table 3 .

Table 7. Computational experiment: examples of discovered regularities

\begin{tabular}{|c|c|c|}
\hline$\#$ & Discovered regularity & Frequency \\
\hline 1 & $\begin{array}{l}\text { IF Seller_type = Manufacturing AND Buyer_type }=\text { Manufacturing } \\
\text { THEN New_Item_type }=\text { product }\end{array}$ & $\begin{array}{l}72 /(6+72)= \\
0.923077\end{array}$ \\
\hline 2 & $\begin{array}{l}\text { IF Seller_type }=\text { Manufacturing AND New_Buyer_type }=\text { Manufactur- } \\
\text { ing THEN New_Item_type }=\text { product }\end{array}$ & $\begin{array}{l}72 /(6+72)= \\
0.923077\end{array}$ \\
\hline 3 & $\begin{array}{l}\text { IF Seller_type }=\text { Manufacturing AND Item_type }=\text { precursor } \\
\text { THEN New_Item_type }=\text { product }\end{array}$ & $\begin{array}{l}152 /(59+152) \\
=0.720379\end{array}$ \\
\hline 4 & $\begin{array}{l}\text { IF Seller_type }=\text { Manufacturing AND Price_Compare }=1 \text { AND } \\
\text { New_Buyer_type }=\text { Trading THEN New_Item_type }=\text { product }\end{array}$ & $\begin{array}{l}47 /(2+47)= \\
0.959184\end{array}$ \\
\hline 5 & $\begin{array}{l}\text { IF Seller_type }=\text { Manufacturing AND Price_Compare }=1 \text { AND } \\
\text { Item_type }=\text { precursor THEN New_Item_type }=\text { product }\end{array}$ & $\begin{array}{l}79 /(5+79)= \\
0.940476\end{array}$ \\
\hline
\end{tabular}

\section{Conclusion}

The method outlined in this paper advances pattern discovery methods that deal with complex (non-numeric) evidences and involve structured objects, text and data in a variety of discrete and continuous scales (nominal, order, absolute and so on). The paper shows potential application of the technique for forensic accounting. The technique combines first-order logic (FOL) and probabilistic semantic inference (PSI). The approach has been illustrated with an example of discovery of suspicious patterns in forensic accounting.

\section{References}

1. Prentice, M., Forensic Services - tracking terrorist networks,2002, Ernst \& Young LLP, UK,http://www.ey.com/global/gcr.nsf/UK/Forensic_Services_tracking terrorist networks

2. Don Vangel and Al James Terrorist Financing: Cleaning Up a Dirty Business, the issue of Ernst \& Young's financial services quarterly, Spring 2002.

http://www.ey.com/GLOBAL/content.nsf/International/Issues \& Perspectives_Library_Terrorist Financing_Cleaning_Up a Dirty Business

3. IRS forensic accounting by TPI, 2002, http://www.tpirsrelief.com/forensic_accounting.htm

4. Chabrow, E. Tracking The Terrorists, Information week, Jan. 14, 2002, http://www.tpirsrelief.com/forensic accounting.htm

5. How Forensic Accountants Support Fraud Litigation, 2002, http://www.fraudinformation.com/forensic_accountants.htm

6. i2 Applications-Fraud Investigation Techniques, http://www.i2.co.uk/applications/fraud.html 
7. Evett, IW., Jackson, G. Lambert, JA, McCrossan, S. The impact of the principles of evidence interpretation on the structure and content of statements. Science \& Justice 2000; 40: 233-239

8. Kovalerchuk, B., Vityaev, E., Data Mining in Finance: Advances in Relational and Hybrid Methods, Kluwer, 2000 